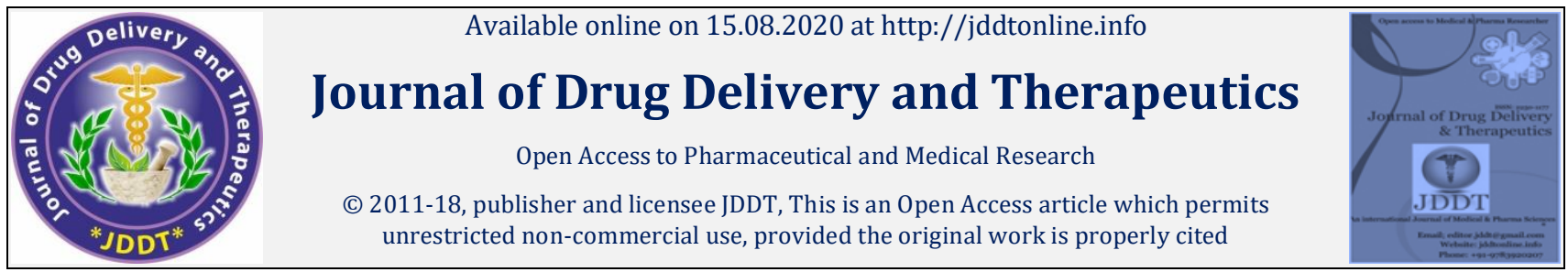

Open Access

Research Article

\title{
Metal Chelating and Cupric Ion Reducing Antioxidant Capacities of Ammoides atlantica Aqueous Extract
}

\section{Karima Loucif ${ }^{*}$, Hassiba Benabdallah'1, Fatima Benchikh¹, Soulaf Mehlous' ${ }^{1}$, Chahrazed Kaoudoune1,2, Chawki Ben Souici ${ }^{3}$ and Smain Amira ${ }^{1}$}

${ }^{1}$ Laboratory of Phytotherapy Applied to Chronic Diseases, Department of Animal Biology and Physiology, Faculty of Nature and Life Sciences, University Ferhat Abbas, Setif-1, 19000, Algeria

2 Laboratory of Environmental Biosurveillance, Faculty of Sciences, Department of Biology, Badji Mokhtar University, 23000-Annaba, Algeria.

${ }^{3}$ Biotechnology Research Center (CRBt), UV 03 BP E73, Nouvelle Ville Ali Mendjli, Constantine, Algeria

\begin{abstract}
Reactive oxygen (ROS) and nitrogen species (RNS) are produced in all cells and play important roles in physiology. The loss of the redox balance, either by an increase of oxidant molecules ROS and RNS or by decreased antioxidant system activities cause a state of oxidative stress. Several studies are going on worldwide directed towards finding natural antioxidants of plant origin. Plants containing phenolic compounds have been reported to possess strong antioxidant activity. The objective of this study is to evaluate total polyphenols and flavonoids contents (TPC and TFC) as well as examine the in vitro antioxidative properties from aqueous extract of Ammoides atlantica (AqE). TPC was estimated utilizing Folin-Ciocalteu's reagent. TFC was evaluated utilizing the aluminum chloride method. The antioxidant properties were evaluated using metal chelating and cupric ion reducing antioxidant capacity (CUPRAC) assays. Indeed, results showed that the AqE is rich in polyphenols (141.74 $\pm 0.44 \mu \mathrm{g}$ gallic acid equivalents/ $\mathrm{mg}$ of dry weight), and flavonoids (61.87 $\pm 6.7 \mu \mathrm{g}$ quercetin equivalent/ mg dry weight). These phytochemical compounds possess significant antioxidant activities. The results showed that AqE exhibited a good Metal chelating activity with an $\mathrm{IC}_{50}$ of $36.57 \pm 4.73 \mu \mathrm{g} / \mathrm{mL}$. CUPRAC assay showed that AqE extract exhibited high cupric ion reducing antioxidant capacity with an $\mathrm{A}_{0.5}$ of $8.58 \pm 0.13 \mu \mathrm{g} / \mathrm{mL}$. These findings provide evidence that AqE of Ammoides atlantica is a potential source of antioxidant which have many benefits towards human health.
\end{abstract}

Keywords: Ammoides atlantica, aqueous extract, phenolic compounds, metal chelating and cupric ion reducing antioxidant capacity.

Article Info: Received 06 June 2020; $\quad$ Review Completed 12 July 2020; $\quad$ Accepted 21 July 2020; $\quad$ Available online 15 August 2020

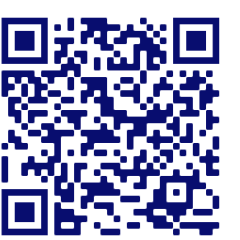

Cite this article as:

Loucif K, Benabdallah H, Benchikh F, Mehlous S, Kaoudoune C, Souici CB, Amira S, Metal Chelating and Cupric Ion Reducing Antioxidant Capacities of Ammoides atlantica Aqueous Extract, Journal of Drug Delivery and Therapeutics. 2020; 10(4-s):108-111 http://dx.doi.org/10.22270/jddt.v10i4-s.4245

Karima Loucif, Laboratory of Phytotherapy Applied to Chronic Diseases, Department of Animal Biology and Physiology, Faculty of Nature and Life Sciences, University Ferhat Abbas, Setif-1, 19000, Algeria

\section{INTRODUCTION}

Oxidative stress is generally characterized by the excess formation of reactive molecules such as ROS (reactive oxygen species). In vivo, some of these ROS play a positive role such as energy production, phagocytosis, regulation of cell growth and intracellular signaling 1 . However, ROS are known to be the major cause of various chronic and degenerative diseases, including aging, coronary heart disease, inflammation, diabetes mellitus and cancer 2 , and can cause cellular injuries and initiate peroxidation of fatty acids in biological membranes. ROS may damage protein ${ }^{3}$, DNA 4 , and enzymes ${ }^{5}$. The antioxidant compounds possess anticarcinogenic, antitumor, anti-inflammatory, antiatherosclerotic, antiviral and antibacterial activities 6 .
Many plant species have been attractive to scientists as natural sources of compounds that are safer than the synthetic ones. Plant-derived antioxidants, especially, the phenolics have gained considerable importance due to their potential health benefits. Previous studies have shown that plant foods containing antioxidants are advantageous to health as it down-regulates certain degenerative processes and can significantly reduce the occurrence of cardiovascular and cancer diseases ${ }^{7}$. The Ammoides atlantica (coss. et Dur.) Wolf, of the family Apiaceae, is widespread in the Mediterranean region and it is endemic in Algeria 8. Traditionally, this plant is known to be used for the therapy of fever and headache, besides its use as antidiarrheic ${ }^{9}$. This study aims to investigate the in vitro antioxidant Activities of 
Ammoides atlantica aqueous extract using metal chelating and cupric ion reducing antioxidant capacity (CUPRAC) assays, besides to evaluate total polyphenol and flavonoids contents.

\section{MATERIALS AND METHODS}

\subsection{Plant material}

\subsubsection{Plant collection and identification}

Ammoides atlantica was harvested at the flowering stage from Jijel north-eastern of Algeria during spring. Aerial parts were dried in shadow at room temperature then powdered and stocked in darkness until use. The authenticity was confirmed by Pr Laouar Hocine (Department of Vegetal Biology and Ecology, University Farhat Abbas Setif 1).

\subsubsection{Extraction procedure}

The extraction process was done according to a method of 8 . $100 \mathrm{~g}$ of Ammoides atlantica powder was mixed with $1 \mathrm{~L}$ of boiling distilled water $\left(100{ }^{\circ} \mathrm{C}\right)$ and after 20 minutes it was removed from the heat. The mixture was filtered using Wattman filter paper $n^{\circ} 1$ and then dried at $45^{\circ} \mathrm{C}$ to obtain aqueous extract which was stored at $20^{\circ} \mathrm{C}$ until further analysis 10 .

\subsection{Determination of total phenolic and flavonoid contents}

\subsubsection{Total phenolic content (TPC)}

The total phenolic content of AqE extract was determined spectrophotometrically using the Folin-Ciocalteu method 11 with some modifications. In a brief description, $100 \mu \mathrm{l}$ of $1: 10$ Folin-Ciocalteau reagent and $75 \mu \mathrm{l}$ of sodium carbonate $(7.5 \%)$ were added to $20 \mu \mathrm{l}$ of aqueous extract. After $2 \mathrm{~h}$ of incubation in the dark at ambient temperature, the absorbance at $765 \mathrm{~nm}$ was measured by a microplate reader, against a control. The total polyphenol content was determined as micrograms of gallic acid equivalent per milligram of extract ( $\mu \mathrm{g} \mathrm{GAE} / \mathrm{mg}$ ).

\subsubsection{Total flavonoids content (TFC)}

TFC was evaluated utilizing the aluminum colorimetric method 12 with some modifications. A volume of $130 \mu \mathrm{l}$ of methanol was transferred into a micro-plate (96 wells) containing $50 \mu \mathrm{l}$ of AqE and then $10 \mu \mathrm{l}$ of potassium acetate $(1 \mathrm{M})$ and $10 \mathrm{ml}$ of aluminum nitrate at $10 \%$ were added. After period incubation for $40 \mathrm{~min}$ at ambient temperature, the absorbance was read at $415 \mathrm{~nm}$ by a micro-plat reader. The standard calibration curve of quercetin at various concentrations was utilized to calculate total flavonoid concentration. The results were presented as micrograms of quercetin equivalent per milligram of extract ( $\mu \mathrm{g} \mathrm{QE} / \mathrm{mg}$ ).

\subsection{Antioxidant activity assays}

\subsubsection{Metal chelating activity assay}

The metal chelating activity by the ferrene-Fe ${ }^{2+}$ complexation assay measured spectrophotometrically 13, 14 with slight modifications. $40 \mu \mathrm{l}$ of the extract were added to $40 \mu \mathrm{l}$ of $0.2 \mathrm{mM} \mathrm{FeCl}_{2}$. The reaction was initiated after the addition of $80 \mu \mathrm{l}$ of ferene solution $(0.5 \mathrm{mM})$. The obtained mixture was shaken then incubated at room ambient for 10 min. The absorbance was read at $593 \mathrm{~nm}$. The metal chelating potential was estimated by the utilize of the following equation. The results were given as $\mathrm{IC}_{50}$ value $(\mu \mathrm{g} / \mathrm{ml})$ (50\% inhibition):

$$
\text { Metal chelating activity }(\%)=\left[\left(\mathrm{A}_{\text {Control }}-\mathrm{A}_{\text {Sample }}\right) / \mathrm{A}_{\text {Control }}\right] \times 100
$$

\subsubsection{Cupric reducing antioxidant capacity (CUPRAC) assay}

The CUPRAC was determined according to the method of 15 . In each well, the reaction mixture containing $40 \mu \mathrm{l}$ of sample and $50 \mu \mathrm{l}$ of a copper (II) chloride solution, $50 \mu \mathrm{l}$ of a neocuproine alcoholic solution, and $60 \mu \mathrm{l}$ of ammonium acetate aqueous buffer at $\mathrm{pH} 7$ was combined to give a final volume of $200 \mu \mathrm{l}$. After 30 minutes, the absorbance was measured at $450 \mathrm{~nm}$. Results were recorded as absorbance $\left(\mathrm{A}_{0.5}\right)$ compared with the absorbance of BHA and BHT, which were used as antioxidant standards.

\subsection{Statistical analysis}

All data were the average of triplicate analyses. Data were recorded as the mean \pm standard deviation. Analysis of variance was executed using Student's t-test or one-way analysis of variance (ANOVA) with the aid of Graph Pad Prism 7.00. $p$ values $<0.05$ were regarded as significant.

\section{RESULTS}

\subsection{Total phenolics and flavonoids contents}

Our results showed that the Ammoides atlantica aqueous extract (AqE) had high polyphenol $(141.74 \pm 0.44 \mu \mathrm{g} \mathrm{GAE} / \mathrm{mg}$ dry extract) and flavonoid $(61.87 \pm 6.7 \mu \mathrm{g} \mathrm{QE} / \mathrm{mg}$ dry extract) contents. (Table 1).

Table 1: Total polyphenols and flavonoids content of Ammoides atlantica aqueous extract. AqE: aqueous extract, (a): $\mu \mathrm{g}$ GAE/mg and (b): $\mu \mathrm{g} \mathrm{QE} / \mathrm{mg}$

\begin{tabular}{|l|l|l|}
\hline Extract & Total phenolic content(a) & Total flavonoid content(b) \\
\hline $\mathrm{AqE}$ & $141.74 \pm 0.44$ & $61.87 \pm 6.7$ \\
\hline
\end{tabular}

\subsection{Antioxidant activity}

\subsubsection{Metal chelating activity}

The antioxidative potential was observed in Ammoides atlantica aqueous extract (AqE) using a metal chelating test as shown in Table 1. This assay showed that the AqE had a strong antioxidant activity with an $\mathrm{IC}_{50}$ of $36.57 \pm 4.73 \mu \mathrm{g} / \mathrm{mL}$ (Table 1).

\subsubsection{Cupric reducing antioxidant capacity (CUPRAC)}

CUPRAC assay showed that the Ammoides atlantica AqE exhibited a good effect with an $A_{0.5}$ of $8.58 \pm 0.13 \mu \mathrm{g} / \mathrm{mL}$. This cupric reducing antioxidant capacity from Ammoides atlantica AqE was similar to that of BHT synthetic antioxidant $(\mathrm{P}>0.05$, no significant difference). But this activity is relatively lower compared to the BHA $(\mathrm{p}<0.0001)$ as standard (Table 1 ). 
Table 2: Antioxidant activities of Ammoides atlantica aqueous extract (AqE). ns : no significant difference and ${ }^{* * * *} \mathrm{p}<0.0001$ compared to correspondent standards. AqE: aqueous extract, BHA: butylated hydroxyanisole, BHT: butylated hydroxytoluene, and EDTA: Ethylenediaminetetraacetic acid.

\begin{tabular}{|c|c|c|}
\hline \multirow{2}{*}{ Extract/standard } & $\mathrm{IC}_{50}(\mu \mathrm{g} / \mathrm{mL})$ & $\mathrm{A}_{0.5}(\mu \mathrm{g} / \mathrm{mL})$ \\
\cline { 2 - 3 } & Metal chelating activity & Cupric reducing antioxidant capacity \\
\hline AqE & $36.57 \pm 4.73$ & $8.58 \pm 0.13$ \\
\hline BHA & $/$ & $3.64 \pm 0.19 * * * *$ \\
\hline BHT & $/$ & $9.62+0.87 \mathrm{~ns}$ \\
\hline EDTA & $12.11+0.32^{* * * *}$ & $/$ \\
\hline
\end{tabular}

\section{DISCUSSION}

In the current study, the antioxidant activity of Ammoides atlantica AqE was evaluated by using metal chelating and CUPRAC assays. Metal ion chelating activity of an antioxidant molecule prevents oxyradical generation and the consequent oxidative damage ${ }^{16}$. Metal ion chelating capacity plays a significant role in antioxidant mechanisms since it reduces the concentration of the catalyzing transition metal in lipid peroxidation ${ }^{17}$. In the presence of chelating agents, the ferrozine- $\mathrm{Fe}^{2}$ complexes are disrupted, resulting in a decrease in the red color of the complex. Ammoides atlantica AqE exhibited a good metal chelating activity. This activity could be attributed to the richness of AqE in polyphenols and flavonoids. Phenolic compounds have been reported to be chelators of free metal ions ${ }^{18}$. CUPRAC method is based on the reaction of an electron transfer, thus the oxidant is reduced, which monitored by a color change 19 . In this assay, the Ammoides atlantica aqueous extract demonstrates a strong antioxidant effect. This cupric reducing antioxidant capacity could be due to phenolic and flavonoid contents in AqE. Several authors have reported that the antioxidant capacity depends on the amount of phenolic compounds of plant extracts. 20, 21. The phenolic compounds acting as hydrogen donors, free radical acceptors, chain oxidation reaction interrupters or metal chelators ${ }^{22}$. This finding of the antioxidant capacity of Ammoides atlantica is in agreement with other studies $23,24,25$.

\section{CONCLUSION}

This work revealed that aqueous extract of the aerial parts of Ammoides atlantica contains high levels of phenolics and flavonoids, and possesses significant antioxidant activities which may due to the presence of polyphenolic compounds. These findings provide scientific support for the traditional uses of Ammoides atlantica. It is also suggested that Ammoides atlantica be viewed as a potential source of natural antioxidants that can provide precious functional ingredients useful for the prevention of diseases related to oxidative stress.

\section{ACKNOWLEDGMENTS}

This work was supported by the Algerian Ministry of Higher Education and Scientific Research (MESRS). We express our gratitude to these organizations. Authors would like also to thank Prof. Hocine LAOUER (Laboratory of Valorization of Natural Biological Resources, University of Sétif1, Algeria) for the identification of the plant material.

\section{REFERENCES}

[1] Halliwell B, Gutteridge JMC, Free radicals in biology and medicine. (3rd ed.). Oxford University Press, New York; 1999. P. 936.

[2] Cheng HY, Lin TC, Yu KH, Yang CM, Lin CC, Antioxidant and free radical scavenging activities of Terminalia chebula, Biol Pharmaceut. Bull., 2003; 26:1331-1335.

[3] Halliwell B, Antioxidants and human disease: A general introduction, Nutr. Rev., 1997; 55:S44-S52.

[4] Bartold PM, Wiebkin OW, Thonard JC, The effect of oxygen-derived free radicals on gingival proteoglycans and hyaluronic acid. J. Periodontology, 1984; 19:390-400.

[5] Varani J, Fligiel SEG, Till GO, Kunkel RG, Ryan VS, Ward PA, Pulmonary endothelial cell killing by human neutrophils: possible involvement of hydroxyl radical. Lab. Invest., 1985; 53:656-663.

[6] Halliwell B, Free radicals, antioxidants, and human disease: curiosity, cause, or consequence?, Lancet, 1994; 344(8924):721-724.

[7] Arabshahi-Delouee S, Urooj A, Antioxidant properties of various solvent extracts of mulberry (Morus indica L.) leaves, Food Chem, 2007; 102: 1233-1240.

[8] Quezel P, Santa S. Nouvelle flore de l'Algérie et des régions désertiques méridionales. Centre National de la Recherche Scientifique, Paris; 1963.

[9] Bellakhdar J. La pharmacopée marocaine traditionnelle. Médecine arabe ancienne et savoirs populaires. Ibiss Press, Paris ; 1997.

[10] Ferreira A, Proença C, Serralheiro ML, Araújo ME, The in vitro screening for acetylcholinesterase inhibition and antioxidant activity of medicinal plants from Portugal, J.Ethnopharmacol, 2006; 108:31-37.

[11] Singleton VL, Rossi JA, Colorimetry of total phenolics with phosphomolybdic phosphotungstic acid reagent, Am J Enol Vitic, 1965; 16:144-58.

[12] Topçu G, Ay A, Bilici A, Sarıkürkcü C, Öztürk M, Ulubelen A, A new flavone from antioxidant extracts of Pistacia terebinthus, Food Chem, 2007; 103(3):816-22.

[13] Decker EA, Welch B, Role of ferritin as a lipid oxidation catalyst in muscle food, J Agric Food Chem, 1990; 38:674-677.

[14] Labed A, Ferhat M, Labed-Zouad I, Kaplaner E, Zerizer S, Voutquenne-Nazabadioko L, Alabdul Magid A, Semra Z, Kabouche A, Kabouche Z, Öztürk M, Compounds from the pods of Astragalus armatus with antioxidant, anticholinesterase, antibacterial and phagocytic activities, Pharm Biol, 2016; 54:3026-3032.

[15] Apak R, Güçlü K, Ozyürek M, Karademir SE. Novel total antioxidant capacity index for dietary polyphenols and vitamins $\mathrm{C}$ and $\mathrm{E}$, using their cupric ion reducing capability in the presence of neocuproine: CUPRAC method, J Agric Food Chem, 2004; 52(26):7970-81.

[16] Benchikh F, Amira S, Benabdallah $H$. The evaluation of antioxidant capacity of different fractions of MyrtuscommunisL.leaves. Annual Research \& Review in Biology 2018; 22 (5):1-14.

[17] Prior R L, Wu X, Schaich K. J, Standardized Methods for the Determination of Antioxidant Capacity and Phenolics in Foods and Dietary Supplements, Agr Food Chem, 2005; 53:4290-4302. 
[18]. Brown J E, Khodr H, Hider RC, Rice-Evans C, Structural dependence of flavonoid interactions with $\mathrm{Cu}^{2+}$ ions: implications for their antioxidant properties, Biochem J, 1998; 330:1173-1178.

[19] Lekouagheta A, Boutefnouchetc A, Bensuicie C, Galie L, Ghenaietb $\mathrm{K}$, Tichati L, In vitro evaluation of antioxidant and anti-inflammatory activities of the hydroalcoholic extract and its fractions from Leuzea conifera L. roots, South African Journal of Botany, 2020; 132:103-107.

[20] Angelov G, Boyadzhiev L, Georgieva S, Antioxydant properties of some Bulgarian wines, J. Int. Sci. Publ, 2008; 3 (1):143-150.

[21] Bozan B, Tosun G, Ozcan D, Study on polyphenol content in the seeds of red grape (Vitis vinifera $\mathrm{L}$.) varieties cultivated in Turkey and their antioxidant activity, Food Chem, 2008; 209:426-430.

[22] Viuda-Martos M, Ruiz Navajas Y, Sanchez Zapata E, Fernandez-Lopez J, Perez-Alvarez JA, Antioxidant activity of essential oils of five spice plants widely used in a Mediterranean diet, Flavour Fragr. J, 2010; 25(1):13-19.

[23] Ababsa ZEA, Benkiki N, Derouiche MT, Louaar S, Medjroubi K, Akka IS, In vivo anti-inflammatory activity of the species: Ammoides atlantica of Apiaceaefamily, Der Pharmacia Lettre, 2011; 3(6):46-48.

[24] Benteldioune M, Boudiar T, Bakhouche A, Contreras MDM, Lozano-Sanchez JL, Bensouici C, Kabouche Z, Segura-Carretero A, Antioxidant activity and characterization of flavonoids and phenolic acids of Ammoides atlantica by RP-UHPLC-ESI-QTOF-MSn, Natural Product Research, 2019:1-5.

[25] Loucif K, Benabdallah H, Benchikh F, Mehlous S, Ben Souici C, Amira S. Total Phenolic Contents, DPPH Radical Scavenging and $\beta$-Carotene Bleaching Activities of Aqueous Extract from Ammoides atlantica, Journal of Drug Delivery and Therapeutics, 2020; 10(3-s):196-198. 